\title{
Ribavirin at the Era of Novel Direct Antiviral Agents for the Treatment of Hepatitis C Virus Infection: Relevance of Pharmacological Monitoring
}

\author{
Pierre Pradat, ${ }^{1,2,3}$ Victor Virlogeux, ${ }^{1,4}$ Marie-Claude Gagnieu, ${ }^{5}$ \\ Fabien Zoulim, 1,2,3,6 and François Bailly ${ }^{1,2,3}$ \\ ${ }^{1}$ Department of Hepatology, Hôpital de la Croix-Rousse, Hospices Civils de Lyon, 103 grande rue de la Croix-Rousse, \\ 69004 Lyon, France \\ ${ }^{2}$ INSERM U1052, 69003 Lyon, France \\ ${ }^{3}$ Université Lyon I, Lyon, France \\ ${ }^{4}$ Ecole Normale Supérieure, 69007 Lyon, France \\ ${ }^{5}$ Department of Pharmacology, Hôpital Edouard Herriot, Hospices Civils de Lyon, 69003 Lyon, France \\ ${ }^{6}$ Institut Universitaire de France, Paris, France
}

Correspondence should be addressed to Pierre Pradat; pradat@univ-lyon1.fr

Received 2 June 2014; Revised 29 August 2014; Accepted 11 September 2014; Published 30 September 2014

Academic Editor: Jun Yong Park

Copyright (C) 2014 Pierre Pradat et al. This is an open access article distributed under the Creative Commons Attribution License, which permits unrestricted use, distribution, and reproduction in any medium, provided the original work is properly cited.

Ribavirin is often used for the treatment of hepatitis $\mathrm{C}$ virus (HCV) infection. Although its mechanisms of action remain to be clearly elucidated, ribavirin plays a beneficial role for achieving virological response and decreasing the rate of virological relapse after treatment cessation. However, ribavirin may induce side effects leading to early treatment discontinuation. Among them, hemolytic anemia is the most frequent and results from intraerythrocyte accumulation. Pharmacological studies have shown that early ribavirin exposure assessed by the area under the curve (AUC) at day 0 and ribavirin trough concentration during the first three months of therapy were correlated with sustained virological response (SVR). These studies highlighted the relevance of ribavirin pharmacologic monitoring and early dose adaptation during therapy. Although the role of ribavirin within new direct acting antiviral (DAA) combinations will probably decrease in the future, its potential benefit in difficult-to-treat patients such as patients with severe hepatopathy or patients who failed triple therapy including patients with multiresistance will need to be further investigated.

\section{Introduction}

Ribavirin (1- $\beta$-D-ribofuranosyl-1,2,4-triazole-3-carboxamide) is a nucleotide analogue of guanosine and a broadspectrum direct antiviral agent (DAA). Ribavirin was discovered 30 years ago and is efficient in vitro and/or in vivo against several RNA or DNA viruses [1-3]. This DAA is mostly used for hepatitis $\mathrm{C}$ virus (HCV) treatment, severe human respiratory syncytial-virus (RSV) infection, some hemorrhagic fevers, and more recently for immunosuppressed patients infected by hepatitis E virus (HEV) [4]. Partly based on the authors' own work [5-13], this paper focuses, in the context of HCV infection, on the ribavirin mechanism of action, its efficacy according to different therapeutic schedules, and its side effects and toxicity. Since clinical and pharmacological data suggest that an adequate and early exposure to ribavirin improves virological response, the relevance of ribavirin pharmacological monitoring in different patient populations and in different therapeutic situations including new promising treatment strategies is also discussed.

\section{Pharmacological Data}

After a single oral dose, three different phases may be distinguished in ribavirin plasma concentration: a quick absorption 
phase with a mean time of 1.5 hours to reach the maximum concentration $\left(C_{\max }\right)$, a quick distribution phase (half-life around 3.7 hours), and a long elimination phase with a last measurable concentration around 100 hours after intake [14, 15]. Ribavirin is assimilated at $90 \%$ with a N1 nucleosidetransporter active mechanism in the proximal small intestine. Its bioavailability is between $45 \%$ and $65 \%$ with an important variability within and between individuals that can reach $30 \%$ after an oral single-dose [16]. Equilibrium state is reached after 4 weeks of multiple dosing and the half-life is 300 hours.

Ribavirin is then carried to every part of the organism and is phosphorylated in the intracellular medium [13]. Ribavirin triphosphate is the major intracellular metabolite. Extracellular transport of ribavirin needs a dephosphorylation process. In erythrocytes, extracellular transport of ribavirin is not possible due to the absence of this dephosphorylation process which explains its intracellular accumulation. Halflife of ribavirin in erythrocyte is 40 days. Its elimination takes place with splenic hemolysis. Renal excretion of ribavirin and its associated metabolites represent only $40 \%$ of its total clearance [17].

Bruchfeld et al. [18] studied ribavirin pharmacokinetics in HCV patients with renal insufficiency. In a study on 63 patients, the authors showed that ribavirin clearance was linearly dependent on renal function with a small nonrenal clearance dependent on body weight and age. Estimated glomerular filtration rate (eGFR) was a better predictor of ribavirin clearance than body weight alone. However, the effect of renal function on ribavirin clearance was only observed for patients with a creatinine clearance under $34 \mathrm{~mL} / \mathrm{min}$. Therefore, prescription of ribavirin with or without interferon (IFN) should be adapted to weight but also to patient's renal function $[19,20]$. In this Swedish work, the authors proposed a ribavirin-dosing schedule based on eGFR and body weight to reach an intended target concentration and concluded that follow-up of concentrations was crucial in patients with renal insufficiency. Other studies have demonstrated that ribavirin clearance was influenced by weight, age, gender, and creatinine but these cofactors could only explain 27 to $40 \%$ of interindividual variability [18, 21]. Metabolism mostly explains mechanisms of ribavirin clearance but sites of clearance remain unknown. Liver could probably play a role although Glue et al. showed that liver failure had no impact on ribavirin clearance. Only mean $C_{\max }$ and ribavirin concentration profiles between 0 and 6 hours were different between the three groups of patients (normal liver function, moderate liver failure, and severe liver failure) [22]. The gastrointestinal tract is the potential candidate for the major site of clearance [14]. Finally high fat meals can increase ribavirin bioavailability by $46 \%$ compared to fasted state [23].

\section{Mechanism of Action}

Ribavirin mechanism of action is still not perfectly elucidated (Figure 1). Ribavirin has an antiviral and immunomodulatory effect and several hypotheses for its antiviral effects have been proposed.
Feld et al. [24] suggested that ribavirin could increase IFN-sensitive target genes activity. A lead-in phase of ribavirin could also promote the expression of these genes that transform cells in more IFN-sensitive cells by increasing the production of endogenous IFN. Similar results were observed in vitro with the respiratory syncytial virus (RSV) [25].

We recently showed that ribavirin could interact in vivo and in vitro with IFN genes expression [10]. We know that activation of these genes before treatment is associated with a poor-probability of response to IFN [26-28]. In vivo, ribavirin treatment reduces the mRNA levels of a large number of interferon stimulated genes (ISGs), particularly those found upregulated in nonresponders to PEG-IFN/ribavirin [10]. This effect was confirmed in vitro in primary human hepatocytes and differentiated HepaRG cells, in which exposure to ribavirin alone resulted in downregulation of a large set of ISGs. Ribavirin, by reducing this activation, could restore the possibility of an endogenous or therapeutic IFN-response in $\mathrm{HCV}$ patients. This ISGs downregulation correlated with liver biochemical response, with a sharper inhibition observed in patients showing ALT normalization following RIBAVIRIN treatment. This mechanism explains the relevance of ribavirin in therapeutic combinations with or without IFN and could explain the biological and histological effects observed in ribavirin monotherapy [12].

These results suggest that a sufficient and early exposition to ribavirin (absorption and distribution) could stimulate IFN mechanisms of action and induce a very early viral load decrease.

Another possible mechanism of action has been proposed. Some studies [29, 30] suggested a dose-dependent mechanism of action on the second slope of viral load decrease among patients with a low IFN efficacy. The authors suggested that ribavirin does not increase mortality rate of infected cells but rather decreases viral infectivity through viral mutagenesis. Ribavirin triphosphate could incorporate in DNA instead of guanosine triphosphate and could in this way increase the replication error rate including lethal mutations of the virus [31]. However, these so-called "error catastrophes" were not confirmed by other studies $[9,11]$.

This mutagenesis process could be weak during monotherapy. However, in presence of IFN, viral production could decrease and relative ribavirin concentration in each viral genome being replicated in infected cells could increase, hereby increasing the mutation rate. In HCV-replicon, ribavirin can inhibit infection of new cells by new produced genomes although replication rate is still the same [29, 30]. However, another study seems to contradict this hypothesis [32].

Two other hypotheses are today less and less considered. Ribavirin could inhibit HCV RNA polymerase by a direct antiviral action as demonstrated in the replicon model. A study by Pawlotsky et al. [33] showed a decrease of the initial viral load of about $0.5 \mathrm{log}$ in some patients treated by ribavirin monotherapy. This decrease was shown to correlate with ribavirin plasma concentration [34]. The other hypothesis is that ribavirin could promote a decrease of 


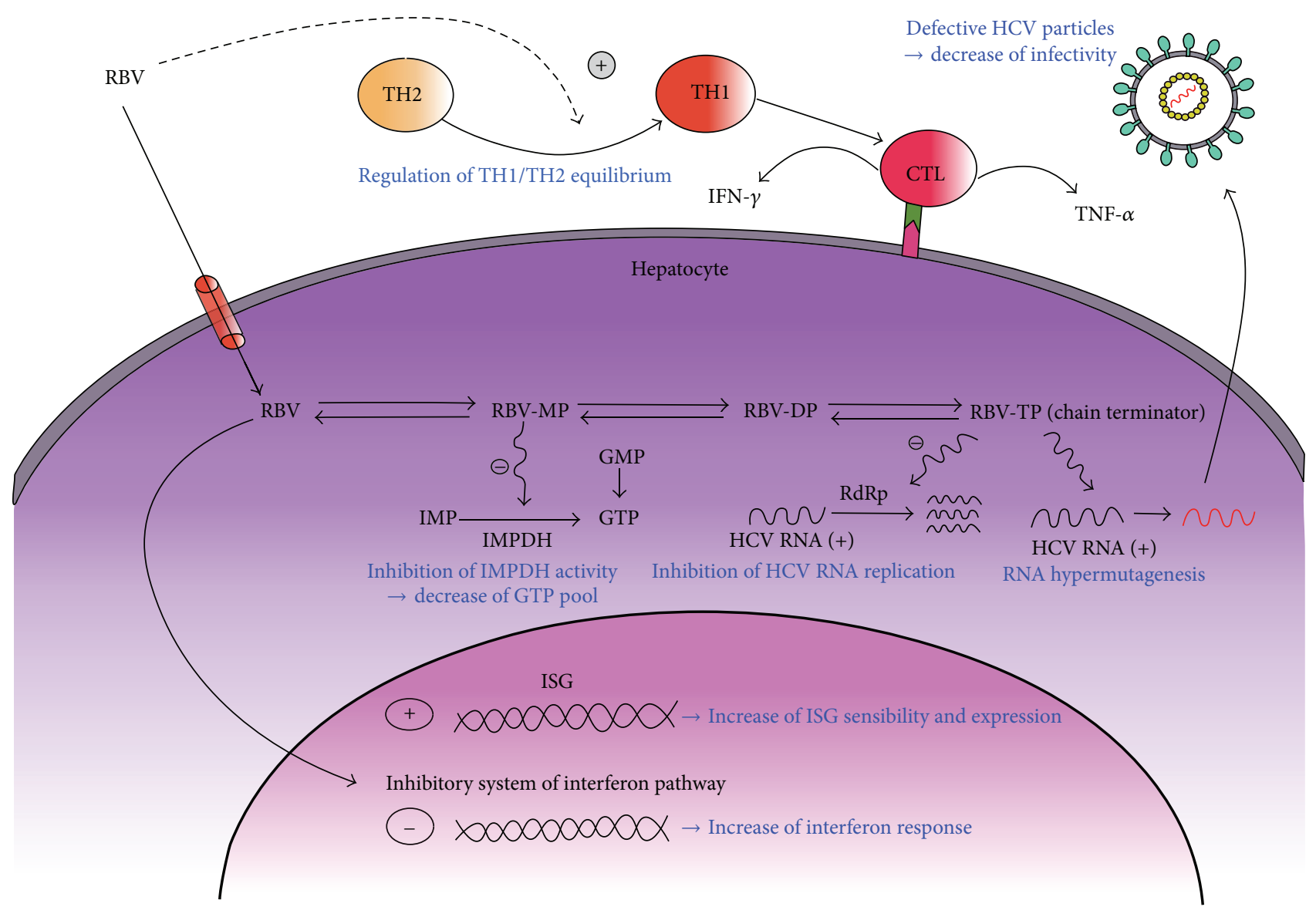

FIGURE 1: Ribavirin mechanism of action.

guanosine triphosphate (GTP) pool. Moreover ribavirin $5^{\prime}$ monophosphate is a strong inhibitor of IMP-dehydrogenase [35], hereby impairing de novo-GTP synthesis necessary for viral replication $[36,37]$.

Finally, ribavirin also has an immunomodulatory role in the positive regulation of auxiliary TH1/TH2 T-lymphocytes. This property could explain the decrease of liver transaminase level during treatment.

\section{Side Effects and Haematological Toxicity}

Ribavirin induces side effects responsible for 3 to $11 \%$ of early treatment cessation that may reach $35 \%$ among cirrhotic patients [12]. These side effects are mostly reversible at the end of treatment. Ribavirin induces in particular allergic reactions such as chronic dry cough or pruritus but the most frequent side effect is haemolytic anaemia due to intraerythrocyte accumulation. During pegylated (PEG)IFN/ribavirin combination therapy, $25 \%$ of patients develop anaemia with haemoglobin level $<10 \mathrm{~g} / \mathrm{dL}$ and $13 \%$ of patients need ribavirin dose modification [38, 39].

This ribavirin-induced anaemia seems to be correlated with ribavirin plasma concentration rather than with the ratio dosage/weight [40]. A Japanese study [41] reported a correlation between the decrease of haemoglobin level and ribavirin plasma concentration but no association between severity of anaemia and initial haemoglobin level was reported.

Several independent studies reported an association between inosine-triphosphate-pyrophosphate (ITPA) genetic polymorphism and a protective effect against ribavirininduced anaemia. ITPA promotes inosine-triphosphate (ITP) hydrolysis in inosine-monophosphate (IMP). Several ITPA gene polymorphisms associated with a defect in ITPA-activity were identified. The induced ITP accumulation could substitute guanosine triphosphate depleted by ribavirin during ATP-synthesis process. In erythrocytes, the depletion of ATP induced by ribavirin gives rise to oxidative stress and erythrocyte lysis. A reduced activity of ITPA could thus have a protective effect against ribavirin-induced anaemia. During combination therapy, lower grades of anaemia were observed in patients with minor variants of ITPA and also in patients under triple therapy with boceprevir or telaprevir [42-44].

Moreover, haptoglobin phenotype was shown to be a determinant factor in ribavirin-induced haemolytic risk [45]. Although the exact mechanism remains speculative, the authors showed that the Hp 1-1 phenotype was associated with a higher hemoglobin drop between week 0 and week 8 of ribavirin exposure. 


\section{Efficacy}

5.1. Efficacy during Monotherapy. After several months of monotherapy, ribavirin induces a progressive normalization of transaminases in 30 to $50 \%$ of cases with a constant relapse at the end of treatment [46]. Histological benefit of long-term regimens has been suggested but has not been confirmed in large-scale studies [12].

In a study by Bonaventure et al. [5], effects of ribavirin monotherapy were evaluated among 83 patients treated for a mean duration of 60 months. Results showed a low antiviral efficacy (median decrease of HCV RNA of $0.2 \mathrm{log}$ ), a biochemical response in $60 \%$ of cases, an histological improvement with $44 \%$ of activity score improvement whatever the treatment response, and a $24 \%$ fibrosis score improvement among patients with normalized transaminases.

\subsection{Efficacy during PEG-IFN/Ribavirin Combination Therapy.} In 1994, Brillanti et al. showed promising results of PEGIFN/ribavirin combination therapy [47]. Ribavirin became afterwards the major drug of anti-HCV IFN-based treatments $[48,49]$ and later on of PEG-IFN based treatments [38, $39,50]$. Combination therapy increased sustained virological response (SVR) rates by $25-30 \%$. This positive effect of ribavirin was associated with a reduction of relapse-rate after the end of treatment. It was suggested that ribavirin prevented relapse by significantly increasing the second slope of HCVRNA decrease [51].

5.3. Efficacy during Triple Therapy. Recent studies combining DAA with ribavirin also suggested a positive effect of ribavirin in such treatment strategies. The first study reporting a potential effect of ribavirin involved the RG1626 nucleoside inhibitor and showed a synergic effect of ribavirin [52].

The benefit of ribavirin in protease inhibitor (PI)-based treatments was reported in an in vitro study [53] and in three large phase-II studies: PROVE II [54] PROVE III [55] and SPRINT-1 [56]. Patients that did not receive ribavirin in PROVE-studies and those with a low ribavirin dosage in SPRINT-1 study had a higher probability of viral breakthrough or relapse and a lower SVR rate. These studies show that standard ribavirin dosage is necessary to get the best response to a first generation PI-based treatment.

5.4. Benefit in IFN-Free Regimens. The usefulness of ribavirin when associated with DAA in IFN-free regimens is still unclear. Some studies showed that IFN-free treatments based on protease or polymerase inhibitors were more efficient when combined with ribavirin $[57,58]$. These studies suggested a benefit of ribavirin when combined with DAA, particularly when associated drugs have a low genetic barrier [59].

Three new DAA (sofosbuvir, daclatasvir, and simeprevir) are now available in western countries and are the basis of new IFN-free combinations. The sofosbuvir/ribavirin combination during 12 weeks is today the standard treatment for genotype 2 infections, with or without cirrhosis, with SVR rates above $90 \%[60,61]$. This combination may also be proposed during 24 weeks in genotype 3 patients or in genotypes 1 or 4 patients in whom PEG-IFN cannot be used [62]. The ribavirin dose seems to impact virological response and it was shown that low doses $(600 \mathrm{mg} /$ day $)$ were associated with lower virological response than weight-based doses (48\% versus 68\%) [63].

Two recent studies assessed the efficacy of a sofosbuvir/simeprevir or sofosbuvir/daclatasvir combination with or without ribavirin in genotype 1 patients with or without cirrhosis. The addition of ribavirin to the sofosbuvir/simeprevir or sofosbuvir/daclatasvir 12-24 week combinations did not improve SVR and was more frequently associated with side effects [64-66]. These results seem to indicate no clear-cut benefit of ribavirin when added to DAA combinations containing a nucleoside polymerase inhibitor with high genetic barrier and another antiviral. However, some preliminary results indicate that such combinations may not be sufficient in difficult-to-treat patients such as genotypes 1 or 3 decompensated cirrhotics and suggest that the addition of ribavirin could improve virological response [67]. The role of ribavirin within new DAA combinations will probably decrease in the future. However, its potential benefit in difficult-to-treat patients (patients with severe hepatopathy or multiresistance) will need to be further investigated.

\section{Ribavirin Monitoring}

Current clinical and pharmacodynamic data suggest that an adequate and early exposure to ribavirin increases SVR and decreases relapse rates.

The main purpose of ribavirin pharmacologic monitoring is to potentially adapt ribavirin dosage. Variability of ribavirin plasma concentrations in relation with the interindividual variability of pharmacokinetic parameters has to be controlled and reduced with ribavirin dosage. Moreover a double relation exists between first ribavirin plasma concentration and antiviral efficacy and secondly between ribavirin plasma concentration and toxicity. Nevertheless, direct correlation between ribavirin dosage and ribavirin plasma concentration does not exist [15]. Weight, gender, age, diet, creatinine level, and other unknown pharmacogenetic factors are probably involved in ribavirin pharmacokinetics [21].

6.1. Plasma or Serum. Most studies about ribavirin focus on ribavirin plasma concentration. However, in vitro ribavirin plasma concentration decreases over time if blood sample is not analysed immediately after collection. This decrease is due to an intraerythrocyte transport of ribavirin with the help of specific equilibrative transporters. This plasma decrease is around $30 \%$ after one hour of storage at room temperature and around $60 \%$ after three hours. The most plausible hypothesis is that ribavirin is still phosphorylated in erythrocytes in vitro inducing this decrease of plasma ribavirin.

Preanalytical phase of ribavirin plasma concentration measures was thus standardised and ribavirin trough plasma concentration is measured from a blood sample stored in ice and centrifuged within 15 minutes after collection. 


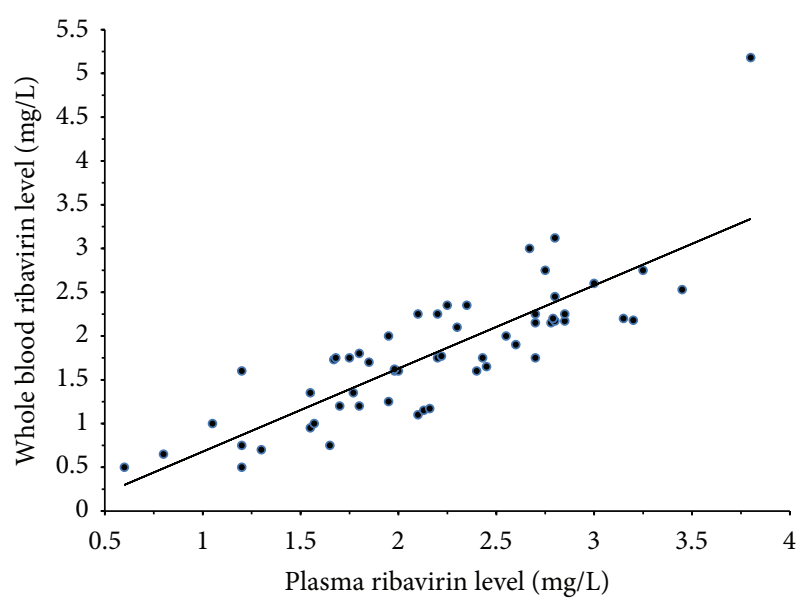

Figure 2: Ribavirin concentration in plasma and in whole blood of 57 patients treated by pegylated interferon/ribavirin (correlation coefficient: $0.841, r 2=0.71,95 \%$ confidence interval $0.743-0.904)$.

6.2. Erythrocyte. Measure of intraerythrocyte ribavirin concentration was suggested to be more relevant [22]. The authors showed that early intraerythrocyte accumulation of ribavirin was higher among patients who achieved SVR. However, irreversible accumulation of ribavirin triphosphate is probably not a good turn-over marker of the drug in the other target cells such as hepatocytes, where the activation of ribavirin in triphosphate metabolite is reversible. Currently, no scientific proof shows that ribavirin intraerythrocyte concentration is better than plasma concentration.

6.3. Whole Blood. We measured ribavirin concentration in frozen whole blood samples immediately after blood sample collection in order to reduce the variability of concentrations during the preanalytical phase. Ribavirin concentrations in frozen whole blood samples were compared with ribavirin plasma concentrations. This comparison was first performed in a pilot study of $57 \mathrm{HCV}$ patients receiving PEGIFN/ribavirin combination therapy. Mean ribavirin concentration in whole blood $(1.89 \pm 0.75 \mathrm{mg} / \mathrm{L})$ was equivalent to mean ribavirin plasma concentration $(2.17 \pm 0.67 \mathrm{mg} / \mathrm{L})$ (Figure 2).

\section{Correlation AUC/Trough Concentra- tion/SVR in Combination Therapy}

First attempts of pharmacokinetics/pharmacodynamic study in the literature are based on single-dosage strategy. Based on a study of 1367 patients, Jen et al. concluded in their response model that ribavirin serum concentration at week 4 (W4) was a predictive factor of SVR. However, this factor was less predictive of SVR than genotype and viral load [68]. Nevertheless the time between ribavirin last intake and blood sample collection was not reported in this study. Larrat et al. also demonstrated a relation between SVR and a single-measure

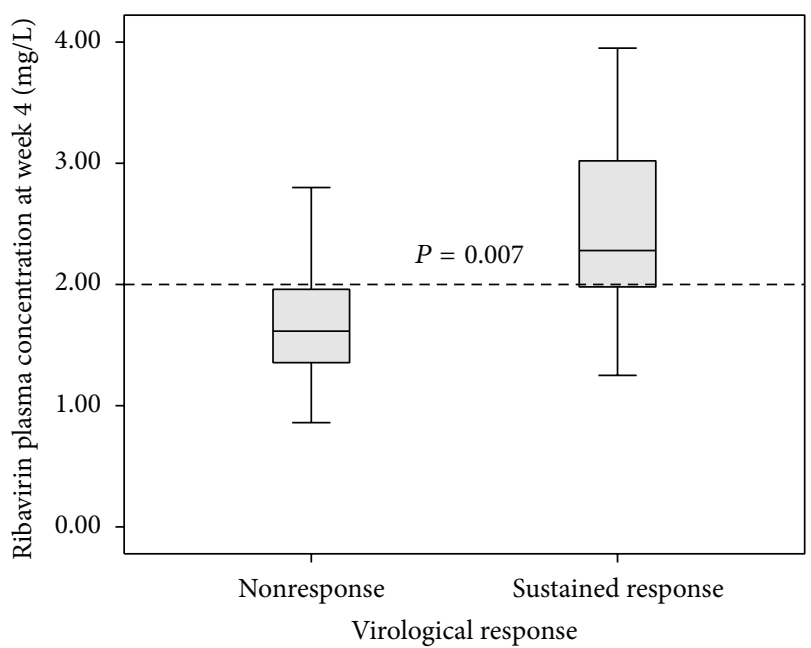

FIGURE 3: Ribavirin plasma concentration at week 4 according to subsequent treatment response. Modified from Maynard et al. [8].

of ribavirin concentration 2-4 hours after the morning intake at W12 of therapy $(n=24 ; P=0.03)$ [69].

Several studies showed that virological response rate to PEG-IFN alpha-2a/alpha-2b combined with ribavirin increased in relation with ribavirin plasma concentration. Initially Jen et al. showed that virological response rate at W24 increased from $30.9 \%$ to $45.2 \%$ for an increase of ribavirin concentration from $1.5 \mathrm{mg} / \mathrm{L}$ to $3.0 \mathrm{mg} / \mathrm{L}$, respectively [21].

An early measure of AUC at day 0 (D0) was proposed as a predictive value of SVR by Loustaud-Ratti et al. [70]. This prospective observational study of $27 \mathrm{HCV}$-genotype 1 infected patients showed that $\mathrm{AUC}_{0-12 \mathrm{~h}}$ and abbreviated $\mathrm{AUC}_{0-4 \mathrm{~h}}$ determined after a first single-dose at D0 was significantly correlated to SVR but also showed that $\mathrm{AUC}_{0-12 \mathrm{~h}}$ at W12 was not. Two threshold values were defined for AUC at D0: $3014 \mu \mathrm{g} / \mathrm{h} / \mathrm{L}$ for $\mathrm{AUC}_{0-12 \mathrm{~h}}$ with a sensitivity of $91 \%$ and a specificity of $61 \%$. For $\mathrm{AUC}_{0-4} \mathrm{~h}$, the threshold value was $1755 \mu \mathrm{g} / \mathrm{h} / \mathrm{L}$ with a sensitivity of $72 \%$ and a specificity of $85 \%$. The assessment of ribavirin $\mathrm{AUC}_{0-4} \mathrm{~h}$ could thus be considered as the most relevant measure due to an easy procedure during ambulatory care of patients and due to a similar predictive value of SVR. For an optimal treatment response, a rapid viral load decrease is necessary during the first weeks or even during the first days of treatment and an early ribavirin dose adjustment thanks to the assessment of ribavirin $\mathrm{AUC}_{0-4 \mathrm{~h}}$ at D0 could significantly increase the SVR rate.

In a prospective study of $31 \mathrm{HCV}$ genotype 1 patients, we showed that a ribavirin trough concentration threshold of $2 \mathrm{mg} / \mathrm{L}$ at W4 was significantly predictive of SVR [8] (Figure 3). ROC curve analysis showed that this treshold was associated with a sensitivity of $73 \%$ and a specificity of $80 \%$. Among patients with a ribavirin concentration $>2 \mathrm{mg} / \mathrm{L}$ at W4, 67\% achieved SVR compared with only $16 \%$ if ribavirin concentration was $<2 \mathrm{mg} / \mathrm{L}(P=0.007)$.

Other studies have evaluated the association between ribavirin concentration and SVR among HCV monoinfected patients. These studies are summarized in Table 1. 
TABLE 1: Summary of studies that evaluated the association between ribavirin concentration (CRBV) or AUC and sustained virological response (SVR) rate among HCV monoinfected patients (modified from Solas et al. [89])

\begin{tabular}{|c|c|}
\hline $\begin{array}{l}\text { Jen et al. [21] } \\
929 \text { naive patients whatever HCV-genotype }\end{array}$ & $\begin{array}{l}\text { CRBV at W4 is a predictive value of SVR. } \\
\text { CRBV at W4 }>3.5-4 \mu \mathrm{g} / \mathrm{mL} \text { is associated with } 49 \% \text { of SVR. }\end{array}$ \\
\hline $\begin{array}{l}\text { Larrat et al. [69] } \\
24 \text { naive HCV genotype } 1 \text { patients }\end{array}$ & $\begin{array}{l}\text { CRBV at W12 and at W24 is significantly higher among patients who achieve } \\
\text { SVR compared to null-responders. } \\
\text { CRBV at } \mathbf{W} \mathbf{1 2} \text { and at } \mathbf{W} \mathbf{2 4}>\mathbf{3} \mu \mathbf{g} / \mathbf{m L} \text { is associated with SVR. }\end{array}$ \\
\hline $\begin{array}{l}\text { Tsubota et al. [90] } \\
27 \text { naive HCV genotype } 1 \text { patients }\end{array}$ & $\mathrm{CRBV}$ at $\mathrm{W} 4>2 \mu \mathrm{g} / \mathrm{mL}$ is predictive of $\mathrm{SVR}$. \\
\hline $\begin{array}{l}\text { Maynard et al. [8] } \\
31 \text { HCV genotype } 1 \text { patients ( } 8 \text { naive and } 23 \\
\text { nonresponder to a previous treatment) }\end{array}$ & $\mathrm{CRBV}$ at $\mathrm{W} 4>2 \mu \mathrm{g} / \mathrm{mL}$ is predictive of $\mathrm{SVR}$. \\
\hline $\begin{array}{l}\text { Arase et al. [91] } \\
68 \text { naive HCV genotype } 1 \text { patients }\end{array}$ & $\mathrm{CRBV}$ at $\mathrm{W} 8>3 \mu \mathrm{g} / \mathrm{mL}$ is predictive of SVR \\
\hline $\begin{array}{l}\text { Lindahl et al. [78] } \\
10 \text { naive HCV genotype } 1 \text { patients }\end{array}$ & $\begin{array}{l}\text { High ribavirin doses were used to achieve a CRBV at W4 }>3.6 \mu \mathrm{g} / \mathrm{mL} \text { and a } \\
\text { CRBV at } \mathrm{W} 12>3.5 \mu \mathrm{g} / \mathrm{mL} \text { in all patients. } 9 / 10 \text { achieved SVR. }\end{array}$ \\
\hline $\begin{array}{l}\text { Loustaud-Ratti et al. [70] } \\
28 \text { naive HCV genotype } 1 \text { patients }\end{array}$ & $\begin{array}{l}\mathrm{AUC}_{0-12 \mathrm{~h}} \text { at D0 correlated with } \mathrm{AUC}_{0-4 \mathrm{~h}} \text { at D0. Both are predictive of SVR. } \\
\mathrm{AUC}_{0-4 \mathrm{~h}} \text { at } \mathrm{DO}>1755 \mu \mathrm{g} \cdot \mathrm{h} / \mathrm{L} \text { is predicitve of SVR }(\mathrm{Se}=72 \% \text { and Spe }=85 \%) \text {. }\end{array}$ \\
\hline Christensen et al. [92] & $\mathrm{CRBV}$ at $\mathrm{W} 4>2 \mu \mathrm{g} / \mathrm{mL}$ is predicitve of SVR $(\mathrm{PPV}=91 \%)$ \\
\hline
\end{tabular}

\section{Relevance of Ribavirin Pharmacologic Monitoring in Specific Therapeutic Situations}

8.1. Patients with Renal Insufficiency or on Dialysis. Standard IFN and then PEG-IFN were used during a long time for $\mathrm{HCV}$ patients with severe renal insufficiency or on dialysis with dose adjustment, whereas ribavirin was contraindicated in these patients [71]. Few data about potential ribavirin dose adjustment are available since the fear of severe hemolytic anaemia led to low rate of ribavirin prescription in these patients. Bruchfeld et al. were among the first who decided to use ribavirin in such patients. Using ribavirin monitoring, they recommended ribavirin doses adapted to impaired renal function [18-20]. Two pilot-studies with, respectively, 6 and 5 patients reported standard IFN/ribavirin treatment results for dialysis patients. Ribavirin dosage was $600 \mathrm{mg} /$ week for the first study and 200-400 mg/day for the second study with EPO supplementation. These two treatment schedules led to an SVR in 9/11 patients. Treatment was stopped in 3 patients due to side effects $[20,72]$, two of them because of anemia, and one because of IFN-related side effects. Thereafter, Bruchfeld and others treated dialysis patients with PEG-IFN/ribavirin combination with adjusted ribavirin dosage but not guided by ribavirin monitoring. Deltenre et al. treated 31 patients with PEG-IFN alpha-2a or alpha-2b in combination with ribavirin [73]. Median ribavirin dosage was $112 \mathrm{mg} /$ day and two EPO-strategies were compared (increase of ribavirin dosage considering haemoglobin level or doubledose of EPO before antiviral treatment initiation). Eighteen to $40 \%$ of patients received transfusion according to the EPO-strategy and SVR was reached in $48 \%$ of cases. More recently, a Taiwanese randomised study compared among dialysis patients a PEG-IFN alpha-2a regimen (135 $\mu \mathrm{g} / \mathrm{week})$ with a PEG-IFN/ribavirin (200 mg/day) combination therapy. Anaemia was more frequent among patients treated by combination therapy but no difference in the rate of treatment discontinuation was observed between both treatment arms. SVR rate was $64 \%$ in the combination therapy arm and $33 \%$ in PEG-IFN treated patients $(P<0.001)$ [74]. More recently, a pilot-study showed that four dialysis patients under telaprevir triple therapy had good virological response and tolerance [6].

In this context, we conducted a retrospective study on patients with renal insufficiency, with or without dialysis and treated with IFN (PEG or standard) and ribavirin.

The aim of this study was to evaluate ribavirin efficacy and safety in these patients. The potential association between virological response and ribavirin plasma concentration at $\mathrm{W} 4$, W8, and W12 was evaluated. A ribavirin plasma concentration threshold was determined in order to get a reference value for adjustment of ribavirin dosage.

Sixty-three HCV patients (40 males and 23 women) with renal insufficiency were included among whom 42 had moderate renal insufficiency $(30<$ creatinine clearance $<$ $60 \mathrm{~mL} / \mathrm{mn})$, four had severe renal insufficiency $(15<$ creatinine clearance $<29$ ), and 17 were on dialysis. Among patients with renal insufficiency 18 had undergone a liver tranplantation and 2 patients had a dual kidney/liver transplantation. Thirteen patients had a kidney transplantation and 10 of them needed dialysis during antiviral treatment. Patients with severe or moderate renal insuficiency were pooled due to the small number of patients in each subgroup. Biological parameters, viral load at W4 and W12, and ribavirin plasma concentration at W4, W8, and W12 were assessed. Dosage at the beginning of treatment, dosage adjustment, side effects (in particular haematological side effect), and early treatment cessation were reported.

Patients' characteristics are presented in Table 2. Data on SVR was not available in three patients. Seven patients had an early treatment withdrawal due to side effects: five due to severe anaemia, one due to IFN intolerance, and one patient died from nonhepatic cause. RVR at W4 and at W12 and SVR 
TABLE 2: Patient characteristics and initial ribavirin dosage.

\begin{tabular}{|c|c|c|}
\hline $\begin{array}{l}\text { Patients } \\
N=63\end{array}$ & $\begin{array}{c}\text { Dialysis patients } \\
(N=17)(\%) \\
\end{array}$ & $\begin{array}{l}\text { Patients with moderate or severe renal insufficiency } \\
\qquad(N=46)(\%)\end{array}$ \\
\hline \multicolumn{3}{|l|}{ HCV genotype } \\
\hline 1 & $10(58.8)$ & $36(78.3)$ \\
\hline 2 & $2(11.8)$ & $4(8.7)$ \\
\hline 3 & $2(11.8)$ & $5(10.5)$ \\
\hline 4 & $3(17.6)$ & $1(2.3)$ \\
\hline \multicolumn{3}{|l|}{ Fibrosis } \\
\hline $\mathrm{F} 0 / \mathrm{F} 1 / \mathrm{F} 2$ & $12(70.6)$ & $29(63.0)$ \\
\hline $\mathrm{F} 3 / \mathrm{F} 4$ & $5(29.4)$ & $17(47.0)$ \\
\hline Mean haemoglobin level (g/dL) [IQR] & 11.9 [9.9-13.7] & $12.7[11.0-15.1]$ \\
\hline Mean ribavirin dosage at $\mathrm{D} 0(\mathrm{mg} /$ day $)$ & 165 & 560 \\
\hline Mean dosage/weight (mg/kg/day) & 2.7 & 10.4 \\
\hline
\end{tabular}

TABLE 3: Virological response for dialysis patients or for patients with renal insufficiency (perprotocol analysis).

\begin{tabular}{|c|c|c|}
\hline $\begin{array}{l}\text { Patients } \\
(N=63)\end{array}$ & $\begin{array}{c}\text { Dialysis patients } \\
(N=17)(\%)\end{array}$ & $\begin{array}{l}\text { Patients with moderate or severe renal insufficiency } \\
\qquad(N=46)(\%)\end{array}$ \\
\hline \multicolumn{3}{|l|}{ Virological response at W12 } \\
\hline EVR & $13 / 17$ & $23 / 46$ \\
\hline RVR & $2 / 17$ & $1 / 46$ \\
\hline cEVR & 7 & 10 \\
\hline pEVR & 4 & 12 \\
\hline Virological response at W24 & $8 / 13(62)$ & $14 / 40(35)$ \\
\hline \multicolumn{3}{|l|}{ HCV genotype } \\
\hline 1 & $4 / 8(50)$ & $8 / 31(26)$ \\
\hline 2 & $2 / 2(100)$ & $3 / 3(100)$ \\
\hline 3 & $1 / 1(100)$ & $3 / 5(60)$ \\
\hline 4 & $1 / 2(50)$ & $0 / 1(0)$ \\
\hline \multicolumn{3}{|l|}{ Fibrosis stage } \\
\hline F0/F1/F2 & $6 / 8(75)$ & $11 / 29(38)$ \\
\hline $\mathrm{F} 3 / \mathrm{F} 4$ & $2 / 5(40)$ & $6 / 11(55)$ \\
\hline Early treatment discontinuation & 2 & 5 \\
\hline Severe anaemia & 1 & 4 \\
\hline Death & 1 & 0 \\
\hline Intolerance to interferon & 0 & 1 \\
\hline
\end{tabular}

cEVR, complete early virological response; EVR, early virological response; pEVR, partial early virological response; RVR, rapid virological response.

in relation to HCV genotype and liver histology are reported in Table 3.

Among dialysis patients $16 / 17$ received EPO before the beginning of antiviral therapy and all received EPO during therapy. EPO doses were increased in $82.4 \%$ of cases. Three patients $(17.6 \%)$ were transfused. A decrease of ribavirin dosage was proposed for $52.9 \%$ of patients. The main reason was a high ribavirin plasma concentration at W4 that could induce severe anaemia. Only one patient stopped treatment because of severe anaemia in a context of orthopedic surgery. In this patient, ribavirin was the probable culprit for the occurrence of anemia.
Among patients with renal insufficiency $39 \%$ received EPO and $8.7 \%(4 / 46)$ were transfused (two of them had severe renal insufficiency). A decrease of ribavirin dosage was proposed for $26 \%$ of patients and temporary treatment withdrawal for $11 \%$. Antiviral therapy was definitively stopped in four patients (8.7\%) due to anaemia despite the use of EPO and/or transfusion. Data on ribavirin plasma concentration at W4, W8, and W12 and treatment response are reported in Table 4. Results indicate that ribavirin plasma concentration was higher in patients with subsequent SVR than in nonresponders or relapsers. Similarly, higher ribavirin levels were observed in patients with rapid virological response (RVR) 
TABLE 4: Mean ribavirin plasma concentration.

\begin{tabular}{|c|c|c|c|c|}
\hline \multirow{2}{*}{$\begin{array}{l}\text { Patients } \\
(N=63) \\
\text { Treatment response }\end{array}$} & \multicolumn{2}{|c|}{$\begin{array}{l}\text { Dialysis patients } \\
\quad(N=17)\end{array}$} & \multicolumn{2}{|c|}{$\begin{array}{l}\text { Moderate or severe renal insufficiency } \\
\qquad(N=46)\end{array}$} \\
\hline & Responder & Nonresponder & Responder & Nonresponder \\
\hline \multicolumn{5}{|l|}{ W4 } \\
\hline EVR & 1.47 & \multirow{2}{*}{0.91} & 2.7 & \multirow{2}{*}{2.36} \\
\hline SVR & 1.26 (RR: 0.56$)$ & & 2.86 (RR: 2.54$)$ & \\
\hline \multicolumn{5}{|l|}{ W8 } \\
\hline EVR & 1.48 & \multirow{2}{*}{1.22} & 2.5 & \multirow{2}{*}{2.15} \\
\hline SVR & 1.38 (RR: 0.8 ) & & 2.76 (RR: 2.31$)$ & \\
\hline \multicolumn{5}{|l|}{ W12 } \\
\hline EVR & 1.65 & \multirow{2}{*}{1.42} & 2.79 & \multirow{2}{*}{3.07} \\
\hline SVR & 1.74 (RR: 1.48$)$ & & 3.22 (RR: 2.43$)$ & \\
\hline
\end{tabular}

compared with those failing to achieve RVR, although these differences did not reach statistical significance. In patients with renal insufficiency (excluding dialysis patients) a ROC curve analysis identified a ribavirin concentration threshold of $2.85 \mathrm{mg} / \mathrm{L}$ at W4 providing the best sensitivity/specificity (Se 71\%, Sp 69\%, NPV 85\%, and PPV 50\%). No association was observed between ribavirin concentration and age, gender, or fibrosis severity.

In this retrospective study and using an intention-to-treat (ITT) strategy, the SVR rate was 53\% in dialysis patients and $31 \%$ in patients with renal insufficiency. Such results with more favorable outcome in dialysis patients were already reported in studies with IFN alone and were thought to be associated with a better IFN bioavailability. However, results in dialysis patients are not as good as those as the Taiwanese study in which patients were treated with PEG-IFN/ribavirin therapy [74]. This difference is at least partly explained by heterogeneous treatments in our cohort since five patients received standard IFN, 27 PEG-IFN alfa-2a, and 21 PEGIFN alfa-2b/ribavirin. Several factors could explain the low response rate observed in patients with renal insufficiency. The first one is a poor tolerance in these patients leading to frequent treatment cessation. The second explanation is a high number of patients with liver transplantation in this group, patients for whom SVR is known to be lower and tolerance poorer.

In dialysis patients, treatment was stopped in only one patient because of a severe anemia following orthopedic surgery. In all other cases, no severe anemia was observed probably because of high EPO doses and ribavirin dose adaptation.

In nondialysis patients the number of treatment cessation was also low since only five patients stopped treatment because of intolerance. A severe anemia was the main cause of treatment withdrawal in four of them. In these patients, anemia continued to worsen after the 4 th week of treatment and did not respond to EPO which was only introduced after anemia appearance. Ribavirin dose reduction and blood transfusion did not help to adequately control the anemic syndrome. The occurrence of severe anemia in patients with severe renal insufficiency or with a creatinine clearance $<40 \mathrm{~mL} / \mathrm{mn}$ could be explained by Bruchfeld results which showed that the effect of renal function on ribavirin clearance only appears for a creatinine clearance $<34 \mathrm{~mL} / \mathrm{mn}$ [18]. Noteworthy in these patients, the EPO use is different than in dialysis patients since it is only initiated at the anemia appearance and not before like in dialysis patients. This late EPO use does not avoid the occurrence of severe anemia because of the action delay of this molecule and also because of the increasing accumulation of ribavirin.

In conclusion, it appears that nondialysis patients with severe renal insufficiency are the most difficult to treat. In these patients, ribavirin pharmacological monitoring, dose adaptation, and growth factor use do not allow treatment continuation. If we want to use ribavirin in these patients, it is probably necessary to introduce EPO early like in dialysis patients. In specific cases, it may be preferable to wait the initiation of dialysis before starting a combination therapy. Interestingly, we observed that ribavirin plasma levels were significantly lower in dialysis patients despite a better virological response rate. These results are in contradiction with previous results showing a link between ribavirin exposure and virological response. These better virological results can at least partly be explained by a better efficacy of IFN.

8.2. HIV-HCV Coinfected Patients. As observed in HCV monoinfected patients, there is in HIV-HCV coinfected subjects an interindividual variability of ribavirin plasma concentrations. In these patients, ribavirin exposure is associated with viral efficacy but also with a risk of developing anemia [75]. A possible explanation for lower SVR rate observed in HIV-HCV coinfected patients could be a lower ribavirin bioavailability in these patients. In a study conducted in our center, in $86 \mathrm{HCV}$ patients treated by PEG-IFN/ribavirin, among whom 23 (27\%) were HIV coinfected, we assessed ribavirin bioavailability (expressed by $\mathrm{AUC}_{0-4 \mathrm{~h}}$ ) after an initial ribavirin dose of $600 \mathrm{mg}$. Blood samples were collected after $30 \mathrm{mn}, 1,2$, and 4 hours [7].

Results show that coinfected patients have a significantly lower ribavirin $\mathrm{AUC}_{0-4 \mathrm{~h}}$ than monoinfected patients. This ribavirin under-exposure in coinfected patients persisted after normalization of AUC to ribavirin dose per kilogram of body weight and was associated with CD4 level with a 
lower AUC in patients with CD4 cell count $<500$ cells $/ \mu \mathrm{L}$. A logistic regression analysis indicated that presence of HIV coinfection and male gender were two independent factors associated with ribavirin under-exposure (defined by AUC $<1755 \mu \mathrm{g} . \mathrm{h} / \mathrm{L}$ ). However, no association appeared between liver disease severity (fibrosis score) or type of antiretroviral treatment (ART) and AUC. These results suggested a lower ribavirin bioavailability in HIV-HCV coinfected patients receiving PEG-IFN/ribavirin treatment which could explain the lower SVR rate observed in these patients. Moreover, these results seemed to be associated with the patient immunological status with similar AUC values in monoinfected patients and in coinfected patients with normal CD4 levels.

Our cohort of HIV-HCV coinfected patients was representative of the HIV population treated at the hospital (57\% with CD4 >500; 87\% with undetectable viral load under HAART; patients mainly receiving 2 NRTI +1 boosted protease inhibitor, ref 104). The choice of the $\mathrm{AUC}_{0-4 \mathrm{~h}}$ was based on the study by Loustaud-Ratti et al. on HCV monoinfected patients in which the authors showed a very good correlation between $\mathrm{AUC}_{0-4 \mathrm{~h}}$ and $\mathrm{AUC}_{0-12 \mathrm{~h}}$ [70].

It was previously recommended to use low ribavirin dose in coinfected patients to avoid toxicity problems associated with other molecules such as zidovudine, stavudine, or didanosine $[76,77]$. However, these drugs are progressively neglected to the benefit of less cytotoxic new antiretroviral drugs. Higher ribavirin dose could thus be used in these patients as suggested in other studies [78, 79]. Our results could suggest specific ribavirin dose adjustments in HIV-HCV coinfected patients, especially according to their immunological status during PEG-IFN based treatment or during new forthcoming treatment strategies.

\section{Ribavirin Pharmacokinetics during Triple Therapy}

The anemia which is frequently encountered during ribavirin-based treatment of hepatitis $\mathrm{C}$ often leads to early treatment modification or withdrawal hereby decreasing the antiviral efficacy. It has been shown that anemia increases during telaprevir exposure [80]. In a study conducted in previous nonresponder HCV patients retreated by telaprevirbased triple therapy, we determined whether telaprevir exposure resulted in increased RIBAVIRIN plasma exposure which could explain the increased incidence of anemia. In parallel, we studied the impact of telaprevir on renal function. Fifty-six HCV patients (among whom 39\% cirrhotics) who were nonresponders to a previous IFN/ribavirin therapy and retreated by PEG-IFN/ribavirin/telaprevir were studied.

Ribavirin plasma concentration was measured before telaprevir initiation during the previous course of PEGIFN/ribavirin combination therapy (T-1), during (at W4 and W8), and after telaprevir treatment (at least 4 weeks after telaprevir withdrawal (W16)).

Ribavirin bioavailability was calculated as the ratio concentration/dosage/body weight.

Our results clearly show a reversible increase of ribavirin bioavailability after telaprevir exposure which might be linked to the parallel impairment of the estimated glomerular filtration rate (eGFR). It is indeed possible that renal dysfunction due to protease inhibitor increases ribavirin bioavailability hereby inducing anaemia.

\section{Discussion}

Since more than 15 years, ribavirin plays an important role in HCV treatment. The mechanism of action is complex and remains poorly understood. It is probable that ribavirin acts at different levels of viral replication. Recent studies suggest an action through the IFN system by stimulating IFN genes hereby enhancing the production of endogenous IFN [10]. It has been clearly shown that ribavirin plays a beneficial role on SVR by an action on the second phase of RNA kinetics during combination therapies and on the decreased frequency of relapse after treatment cessation [51]. Early pivotal trials of combination therapy have shown that a minimal ribavirin dose was necessary to achieve SVR. Later on, pharmacological studies have shown that ribavirin trough concentration during the first three months of therapy was correlated with SVR $[68,69]$. These studies have defined a threshold predicting response. In parallel, a French team showed that early ribavirin exposure defined by AUC at day 0 was predictive of response [70]. Altogether these results suggested therapeutic strategies based on ribavirin pharmacologic monitoring. However, based on ribavirin pharmacokinetics, the impact on ribavirin exposure only occurs about 4 weeks after dose modification. Therefore, if a ribavirin underexposure is present, it will be observed by ribavirin monitoring only after 4 weeks and the impact of a dose increase will not occur before 8 to 12 weeks which is probably too late. This observation is in favor of rather using the AUC at day 0 to early adapt ribavirin dose.

Another approach consisted in initiating treatment with a ribavirin monotherapy before starting IFN treatment [8183]. This strategy allowed to introduce IFN when the ribavirin equilibrium was reached, when the ribavirin exposure was satisfactory, and when the action on IFN stimulating genes was effective. However, no study could definitely confirm the efficacy of this strategy in clinical practice. One possible explanation could be the substantial interindividual variability in the ribavirin metabolism. Even if ribavirin pharmacologic monitoring cannot be widely recommended to adapt ribavirin-based treatments, this monitoring may be useful in specific population, especially those with poor ribavirin tolerance. As we previously mentioned it, this is the case in patients with renal insufficiency or patients on dialysis and also in transplanted patients. This is also true in hemolytic pathologies, especially hemoglobinopathies such as thalassemia.

During telaprevir based treatment, the severity of anemia is associated both with toxicity of telaprevir which probably induces a central anemia and with the ribavirin-induced hemolysis [80]. We have shown that ribavirin bioavailability and thus hemolysis were increased after exposure with telaprevir because of a decreased eGFR and also because of a possible pharmacologic interaction (unpublished data). Current recommendations for the management of these 
anemia under triple therapy suggest the early reduction of ribavirin dose whether or not HCV RNA negativation has been achieved [84]. We have shown previously that these recommendations were based on studies with small numbers of cirrhotic patients. French recommendations suggest to avoid a too early decrease of ribavirin dose in patients with detectable RNA, especially if they are cirrhotics [85]. In this context, ribavirin pharmacologic monitoring may play a major role in accurately assessing ribavirin bioavailability and in deciding on a potential ribavirin dose adaptation.

Novel shorter and well tolerated therapeutic strategies based on new DAA are very promising with viral eradication in more than $90 \%$ of cases. In this context, the role of IFN within these new therapeutic associations will rapidly decrease. However, numerous protocols combining two or three DAA still include ribavirin [86, 87]. Moreover, ribavirin is proposed as a combination therapy with a nucleosidic polymerase inhibitor (sofosbuvir) for the treatment of genotypes 2 and 3 infections $[86,88]$. The tolerance of ribavirin seems to be better with this type of association although most treated patients did not have comorbidities or advanced cirrhosis. Results on efficacy are very good in genotype 2 infected patients but are more heterogeneous in case of genotype 3 infection. In this context, ribavirin pharmacologic monitoring could be relevant.

Although the role of ribavirin within new DAA combinations will probably decrease in the future, its potential benefit in difficult-to-treat patients (patients with severe hepatopathy or patients who failed triple therapy including patients with multiresistance) will need to be further investigated.

\section{Conflict of Interests}

The authors declare that there is no conflict of interests regarding the publication of this paper.

\section{References}

[1] M. Hosoya, S. Shigeta, T. Ishii, H. Suzuki, and E. de Clercq, "Comparative inhibitory effects of various nucleoside and nonnucleoside analogues on replication of influenza virus types A and B in vitro and in ovo," The Journal of Infectious Diseases, vol. 168, no. 3, pp. 641-646, 1993.

[2] S. Shigeta, S. Mori, M. Baba et al., "Antiviral activities of ribavirin, 5-ethynyl-1- $\beta$-D- ribofuranosylimidazole-4-carboxamide, and 6'-(R)-6'-C-methylneplanocin A against several orthoand paramyxoviruses," Antimicrobial Agents and Chemotherapy, vol. 36, no. 2, pp. 435-439, 1992.

[3] R. W. Sidwell, J. H. Huffman, G. P. Khare, L. B. Allen, J. T. Witkowski, and R. K. Robins, "Broad-spectrum antiviral activity of virazole: $1-\beta$-D-ribofuranosyl-1, 2,4-triazole-3-carboxamide," Science, vol. 177, no. 4050, pp. 705-706, 1972.

[4] N. Kamar, L. Rostaing, F. Abravanel et al., "Ribavirin therapy inhibits viral replication on patients with chronic hepatitis e virus infection," Gastroenterology, vol. 139, no. 5, pp. 1612-1618, 2010.

[5] C. Bonaventure, V. Calay, M. Chevallier, P. Merle, P. Pradat, and C. Trepo, "Long-term ribavirin monotherapy in patients with chronic hepatitis $\mathrm{C}$ not responding or intolerant to interferon alpha," Journal of Hepatology, vol. 40, pp. 152-153, 2004.
[6] J. Dumortier, O. Guillaud, M.-C. Gagnieu et al., "Anti-viral triple therapy with telaprevir in haemodialysed HCV patients: is it feasible?" Journal of Clinical Virology, vol. 56, no. 2, pp. 146149, 2013.

[7] G. Hatu, F. Bailly, E. Pourcelot et al., "Lower ribavirin biodisponibility in patients with HIV-HCV coinfection in comparison with HCV monoinfected patients," BMC Infectious Diseases, vol. 14, no. 1, article 150, 2014.

[8] M. Maynard, P. Pradat, M.-C. Gagnieu, C. Souvignet, and C. Trepo, "Prediction of sustained virological response by ribavirin plasma concentration at week 4 of therapy in hepatitis $C$ virus genotype 1 patients," Antiviral Therapy, vol. 13, no. 4, pp. 607611, 2008.

[9] F. Querenghi, Q. Yu, G. Billaud, G. Maertens, C. Trépo, and F. Zoulim, "Evolution of hepatitis $\mathrm{C}$ virus genome in chronically infected patients receiving ribavirin monotherapy," Journal of Viral Hepatitis, vol. 8, no. 2, pp. 120-131, 2001.

[10] B. Testoni, D. Durantel, M. Levrero, and F. Zoulim, "In vivo ribavirin effects on interferon stimulated genes transcriptional regulation involves chromatin remodeling and histone methylation mediated by the G9a methyl-transferase," Journal of Hepatology, vol. 58, supplement 1, p. S5, 2013.

[11] I. Vuillermoz, E. Khattab, E. Sablon et al., "Genetic variability of hepatitis $\mathrm{C}$ virus in chronically infected patients with viral breakthrough during interferon-ribavirin therapy," Journal of Medical Virology, vol. 74, no. 1, pp. 41-53, 2004.

[12] F. Zoulim, J. Haem, S. Si Ahmed et al., "Ribavirin monotherapy in patients with chronic hepatitis C: a retrospective study of 95 patients," Journal of Viral Hepatitis, vol. 5, no. 3, pp. 193-198, 1998.

[13] M. Gagnieu, C. Souvignet, P. Rojat et al., "Blood distribution of non-phosphorylated and phosphorylated forms of ribavirin in patients treated for chronic hepatitis C," Journal of Clinical Virology, vol. 36, p. S135, 2006.

[14] N. M. Dixit and A. S. Perelson, "The metabolism, pharmacokinetics and mechanisms of antiviral activity of ribavirin against hepatitis C virus," Cellular and Molecular Life Sciences, vol. 63, no. 7-8, pp. 832-842, 2006.

[15] P. Glue, "The clinical pharmacology of ribavirin," Seminars in Liver Disease, vol. 19, no. 1, pp. 17-24, 1999.

[16] S. L. Preston, G. L. Drusano, P. Glue, J. Nash, S. K. Gupta, and P. McNamara, "Pharmacokinetics and absolute bioavailability of ribavirin in healthy volunteers as determined by stable-isotope methodology," Antimicrobial Agents and Chemotherapy, vol. 43, no. 10, pp. 2451-2456, 1999.

[17] J.-C. Duclos-Vallée and D. Samuel, "Ribavirin," Médecine Thérapeutique, vol. 6, no. 8, pp. 664-668, 2000.

[18] A. Bruchfeld, K. Lindahl, R. Schvarcz, and L. Ståhle, "Dosage of ribavirin in patients with hepatitis $\mathrm{C}$ should be based on renal function: a population pharmacokinetic analysis," Therapeutic Drug Monitoring, vol. 24, no. 6, pp. 701-708, 2002.

[19] A. Bruchfeld, K. Lindahl, L. Ståhle, M. Söderberg, and R. Schvarcz, "Interferon and ribavirin treatment in patients with hepatitis C-associated renal disease and renal insufficiency," Nephrology Dialysis Transplantation, vol. 18, no. 8, pp. 1573$1580,2003$.

[20] A. Bruchfeld, L. Ståhle, J. Andersson, and R. Schvarcz, "Ribavirin treatment in dialysis patients with chronic hepatitis $\mathrm{C}$ virus infection-a pilot study," Journal of Viral Hepatitis, vol. 8, no. 4, pp. 287-292, 2001.

[21] J. F. Jen, P. Glue, S. Gupta, D. Zambas, and G. Hajian, "Population pharmacokinetic and pharmacodynamic analysis 
of ribavirin in patients with chronic hepatitis C," Therapeutic Drug Monitoring, vol. 22, no. 5, pp. 555-565, 2000.

[22] H. Dahari, M. Markatou, M. Zeremski et al., "Early ribavirin pharmacokinetics, HCV RNA and alanine aminotransferase kinetics in $\mathrm{HIV} / \mathrm{HCV}$ co-infected patients during treatment with pegylated interferon and ribavirin," Journal of Hepatology, vol. 47, no. 1, pp. 23-30, 2007.

[23] S. Khakoo, P. Glue, L. Grellier et al., "Ribavirin and interferon alfa-2b in chronic hepatitis C: assessment of possible pharmacokinetic and pharmacodynamic interactions," British Journal of Clinical Pharmacology, vol. 46, no. 6, pp. 563-570, 1998.

[24] J. J. Feld, S. Nanda, Y. Huang et al., "Hepatic gene expression during treatment with peginterferon and ribavirin: identifying molecular pathways for treatment response," Hepatology, vol. 46, no. 5, pp. 1548-1563, 2007.

[25] Y. Zhang, M. Jamaluddin, S. Wang et al., "Ribavirin treatment up-regulates antiviral gene expression via the interferon-stimulated response element in respiratory syncytial virus-infected epithelial cells," Journal of Virology, vol. 77, no. 10, pp. 5933-5947, 2003.

[26] M. Sarasin-Filipowicz, E. J. Oakeley, F. H. T. Duong et al., "Interferon signaling and treatment outcome in chronic hepatitis C," Proceedings of the National Academy of Sciences of the United States of America, vol. 105, no. 19, pp. 7034-7039, 2008.

[27] M. S. Sixtos-Alonso, F. Sánchez-Muñoz, J. F. Sánchez-Ávila et al., "IFN-stimulated gene expression is a useful potential molecular marker of response to antiviral treatment with pegIFN $\alpha 2 \mathrm{~b}$ and ribavirin in patients with hepatitis $\mathrm{C}$ virus genotype 1," Archives of Medical Research, vol. 42, no. 1, pp. 2833, 2011.

[28] X. Su, L. J. Yee, K. Im et al., "Association of single nucleotide polymorphisms in interferon signaling pathway genes and interferon-stimulated genes with the response to interferon therapy for chronic hepatitis C," Journal of Hepatology, vol. 49, no. 2, pp. 184-191, 2008.

[29] Y. Asahina, N. Izumi, N. Enomoto et al., "Mutagenic effects of ribavirin and response to interferon/ribavirin combination therapy in chronic hepatitis C," Journal of Hepatology, vol. 43, no. 4, pp. 623-629, 2005.

[30] S. Zhou, R. Liu, B. M. Baroudy, B. A. Malcolm, and G. R. Reyes, "The effect of ribavirin and IMPDH inhibitors on hepatitis C virus subgenomic replicon RNA," Virology, vol. 310, no. 2, pp. 333-342, 2003.

[31] S. Crotty, D. Maag, J. J. Arnold et al., "The broad-spectrum antiviral ribonucleoside ribavirin is an RNA virus mutagen," Nature Medicine, vol. 6, no. 12, pp. 1375-1379, 2000.

[32] S. Chevaliez, R. Brillet, E. Lázaro, C. Hézode, and J.-M. Pawlotsky, "Analysis of ribavirin mutagenicity in human hepatitis C virus infection," Journal of Virology, vol. 81, no. 14, pp. 77327741, 2007.

[33] J.-M. Pawlotsky, H. Dahari, A. U. Neumann et al., "Antiviral action of ribavirin in chronic hepatitis C," Gastroenterology, vol. 126, no. 3, pp. 703-714, 2004.

[34] H. M. Dixit, J. E. Layden-Almer, T. J. Layden, and A. S. Perelson, "Modelling how ribavirin improves interferon response rates in hepatitis C virus infection," Nature, vol. 432, no. 7019, pp. 922924, 2004.

[35] S. Stridh, "Determination of ribonucleoside triphosphate pools in influenza A virus-infected MDCK cells," Archives of Virology, vol. 77, no. 2-4, pp. 223-229, 1983.
[36] W. E. G. Mueller, A. Maidhof, H. Taschner, and R. K. Zahn, "Virazole (1-beta-D-ribofuranosyl-1,2,4-triazole-3-carboxamide; a cytostatic agent," Biochemical Pharmacology, vol. 26, no. 11, pp. 1071-1075, 1977.

[37] D. G. Streeter, J. T. Witkowski, G. P. Khare et al., "Mechanism of action of 1- $\beta$-D-ribofuranosyl-1,2,4-triazole-3-carboxamide (Virazole), a new broad-spectrum antiviral agent," Proceedings of the National Academy of Sciences of the United States of America, vol. 70, no. 4, pp. 1174-1178, 1973.

[38] M. W. Fried, M. L. Shiffman, K. Rajender Reddy et al., "Peginterferon alfa-2a plus ribavirin for chronic hepatitis $\mathrm{C}$ virus infection," The New England Journal of Medicine, vol. 347, no. 13, pp. 975-982, 2002.

[39] M. P. Manns, J. G. McHutchison, S. C. Gordon et al., "Peginterferon alfa-2b plus ribavirin compared with interferon alfa$2 \mathrm{~b}$ plus ribavirin for initial treatment of chronic hepatitis $\mathrm{C}$ : a randomised trial," The Lancet, vol. 358, no. 9286, pp. 958-965, 2001.

[40] K. Lindahl, R. Schvarcz, A. Bruchfeld, and L. Ståhle, "Evidence that plasma concentration rather than dose per kilogram body weight predicts ribavirin-induced anaemia," Journal of Viral Hepatitis, vol. 11, no. 1, pp. 84-87, 2004.

[41] H. Igarashi, S. Shinozaki, and T. Mukada, "Serum ribavirin concentration and related anemia interrupting ribavirin plus interferon combination therapy in patients with chronic hepatitis C," Liver International, vol. 24, supplement 4, article 60, 2004.

[42] J. Fellay, A. J. Thompson, D. Ge et al., "ITPA gene variants protect against anaemia in patients treated for chronic hepatitis C," Nature, vol. 464, no. 7287, pp. 405-408, 2010.

[43] M. Kawaguchi-Suzuki and R. F. Frye, "The role of pharmacogenetics in the treatment of chronic hepatitis C infection," Pharmacotherapy, vol. 34, no. 2, pp. 185-201, 2014.

[44] A. J. Thompson, J. Fellay, K. Patel et al., "Variants in the ITPA gene protect against ribavirin-induced hemolytic anemia and decrease the need for ribavirin dose reduction," Gastroenterology, vol. 139, no. 4, pp. 1181.e2-1189.e2, 2010.

[45] H. van Vlierberghe, J. R. Delanghe, M. ve Vos, and G. LerouxRoel, "Factors influencing ribavirin-induced hemolysis," Journal of Hepatology, vol. 34, no. 6, pp. 911-916, 2001.

[46] O. Reichard, J. Andersson, R. Schvarcz, and O. Weiland, "Ribavirin treatment for chronic hepatitis C," The Lancet, vol. 337, no. 8749, pp. 1058-1061, 1991.

[47] S. Brillanti, J. Garson, M. Foli et al., "A pilot study of combination therapy with ribavirin plus interferon alfa for interferon alfa-resistant chronic hepatitis C," Gastroenterology, vol. 107, no. 3, pp. 812-817, 1994.

[48] J. G. Mchutchison, S. C. Gordon, E. R. Schiff et al., "Interferon alfa-2b alone or in combination with ribavirin as initial treatment for chronic hepatitis C," The New England Journal of Medicine, vol. 339, no. 21, pp. 1485-1492, 1998.

[49] O. Reichard, G. Norkrans, A. Frydén, J.-H. Braconier, A. Sönnerborg, and O. Weiland, "Randomised, double-blind, placebo-controlled trial of interferon $\alpha$-2b with and without ribavirin for chronic hepatitis C," The Lancet, vol. 351, no. 9096, pp. 83-87, 1998.

[50] S. J. Hadziyannis, H. Sette Jr., T. R. Morgan et al., "eginterferon$\alpha 2 \mathrm{a}$ and ribavirin combination therapy in chronic hepatitis $\mathrm{C}$ : a randomized study of treatment duration and ribavirin dose," Annals of Internal Medicine, vol. 140, no. 5, pp. 346-I67, 2004.

[51] J.-P. Bronowicki, D. Ouzan, T. Asselah et al., "Effect of ribavirin in genotype 1 patients with hepatitis $\mathrm{C}$ responding to pegylated 
interferon alfa-2a plus ribavirin," Gastroenterology, vol. 131, no. 4, pp. 1040-1048, 2006.

[52] P. J. Pockros, D. Nelson, E. Godofsky et al., "R1626 plus peginterferon Alfa-2a provides potent suppression of hepatitis $\mathrm{C}$ virus RNA and significant antiviral synergy in combination with ribavirin," Hepatology, vol. 48, no. 2, pp. 385-397, 2008.

[53] W. P. Hofmann, T. L. Chung, C. Osbahr et al., "Impact of ribavirin on HCV replicon RNA decline during treatment with interferon- $\alpha$ and the protease inhibitors boceprevir or telaprevir," Antiviral Therapy, vol. 16, no. 5, pp. 695-704, 2011.

[54] C. Hézode, N. Forestier, G. Dusheiko et al., "Telaprevir and peginterferon with or without ribavirin for chronic $\mathrm{HCV}$ infection," The New England Journal of Medicine, vol. 360, no. 18, pp. 1839-1850, 2009.

[55] J. G. McHutchison, M. P. Manns, A. J. Muir et al., "Telaprevir for previously treated chronic HCV infection," The New England Journal of Medicine, vol. 362, no. 14, pp. 1292-1303, 2010.

[56] P. Y. Kwo, E. J. Lawitz, J. McCone et al., "Efficacy of boceprevir, an NS3 protease inhibitor, in combination with peginterferon alfa- $2 \mathrm{~b}$ and ribavirin in treatment-naive patients with genotype 1 hepatitis C infection (SPRINT-1): an open-label, randomised, multicentre phase 2 trial," The Lancet, vol. 376, pp. 705-716, 2010.

[57] S. Zeuzem, T. Asselah, P. Angus et al., "Efficacy of the protease inhibitor BI 201335, polymerase inhibitor BI 207127, and ribavirin in patients with chronic HCV infection," Gastroenterology, vol. 141, no. 6, pp. 2047-2055, 2011.

[58] S. Zeuzem, P. Buggisch, K. Agarwal et al., "The protease inhibitor, GS-9256, and non-nucleoside polymerase inhibitor tegobuvir alone, with ribavirin, or pegylated interferon plus ribavirin in hepatitis C," Hepatology, vol. 55, no. 3, pp. 749-758, 2012.

[59] A. M. Di Bisceglie, D. R. Nelson, E. Gane et al., "VX-222 with TVR alone or in combination with peginterferon alfa-2a and ribavirin in treatment-naive patients with chronic hepatitis $\mathrm{C}$ : ZENITH study interim results," Journal of Hepatology, vol. 54, supplement 1, p. s540, 2011.

[60] J. P. H. Drenth, "HCV treatment-no more room for interferonologists?" The New England Journal of Medicine, vol. 368, no. 20, pp. 1931-1932, 2013.

[61] I. M. Jacobson, S. C. Gordon, K. V. Kowdley et al., "Sofosbuvir for hepatitis $\mathrm{C}$ genotype 2 or 3 in patients without treatment options," The New England Journal of Medicine, vol. 368, no. 20, pp. 1867-1877, 2013.

[62] EASL Recommendations on Treatment of Hepatitis C, 2014, http://files.easl.eu/easl-recommendations-on-treatment-ofhepatitis-C.pdf.

[63] A. Osinusi, E. G. Meissner, Y. J. Lee et al., "Sofosbuvir and ribavirin for hepatitis $\mathrm{C}$ genotype 1 in patients with unfavorable treatment characteristics a randomized clinical trial," Journal of the American Medical Association, vol. 310, no. 8, pp. 804-811, 2013.

[64] E. Lawitz, R. Ghalib, M. Rodriguez-Torres et al., "Simeprevir plus sofosbuvir with/withour ribavirin in HCV genotype 1 prior null-responder/treatment-naive patients (COSMOS study): primary endpoint (SVR12) results in patiens with METAVIR F3-4 (cohort 2)," Journal of Hepatology, vol. 60, supplement, p. S524, 2014.

[65] M. Sulkowski, I. M. Jacobson, R. Ghalib et al., "Once-daily simeprevir (TMC435) plus sofosbuvir (GS-7977) with or without ribavirin in HCV genotype 1 prior null responders with
METAVIR F0-2: COSMOS study subgroup analysis," Journal of Hepatology, vol. 60, supplement, article S4, 2014.

[66] M. S. Sulkowski, D. F. Gardiner, M. Rodriguez-Torres et al., "Daclatasvir plus sofosbuvir for previously treated or untreated chronic HCV infection," The New England Journal of Medicine, vol. 370, no. 3, pp. 211-221, 2014.

[67] E. J. Gane, R. H. Hyland, D. An et al., "Sofosbuvir/ledipasvir fixed dose combination is safe and effective in difficult-totreat populations including genotype- 3 patients, decompensated genotype-1 patients, and genotype-1 patients with prior sofosbuvir treatment experience," Journal of Hepatology, vol. 60, no. 1, supplement, pp. S3-S4, 2014.

[68] J. Jen, M. Laughlin, C. Chung et al., "Ribavirin dosing in chronic hepatitis C: application of population pharmacokineticpharmacodynamic models," Clinical Pharmacology and Therapeutics, vol. 72, no. 4, pp. 349-361, 2002.

[69] S. Larrat, F. Stanke-Labesque, A. Plages, J.-P. Zarski, G. Bessard, and C. Souvignet, "Ribavirin quantification in combination treatment of chronic hepatitis C," Antimicrobial Agents and Chemotherapy, vol. 47, no. 1, pp. 124-129, 2003.

[70] V. Loustaud-Ratti, S. Alain, A. Rousseau et al., "Ribavirin exposure after the first dose is predictive of sustained virological response in chronic hepatitis C," Hepatology, vol. 47, no. 5, pp. 1453-1461, 2008.

[71] C. E. Gordon, K. Uhlig, J. Lau, C. H. Schmid, A. S. Levey, and J. B. Wong, "Interferon treatment in hemodialysis patients with chronic hepatitis $\mathrm{C}$ virus infection: a systematic review of the literature and meta-analysis of treatment efficacy and harms," The American Journal of Kidney Diseases, vol. 51, no. 2, pp. 263277, 2008.

[72] A. C. Tan, J. T. Brouwer, P. Glue et al., "Safety of interferon and ribavirin therapy in haemodialysis patients with chronic hepatitis C: results of a pilot study," Nephrology Dialysis Transplantation, vol. 16, no. 1, pp. 193-195, 2001.

[73] P. Deltenre, C. Moreno, A. Tran et al., "Anti-viral therapy in haemodialysed HCV patients: efficacy, tolerance and treatment strategy," Alimentary Pharmacology and Therapeutics, vol. 34, no. 4, pp. 454-461, 2011.

[74] C. H. Liu, C. C. Liang, T. H. Su et al., "Peginterferon alfa-2a plus low dose ribavirin versus peginterferon alfa-2a monotherapy for dialysis patients with hepatitis $\mathrm{C}$ virus genotype 1 infection: a randomized trial," Hepatology, vol. 56, supplement 1, p. 993A, 2012.

[75] A. L. Rendón, M. Nuñez, M. Romero et al., "Early monitoring of ribavirin plasma concentrations may predict anemia and early virologic response in HIV/hepatitis c virus-coinfected patients," Journal of Acquired Immune Deficiency Syndromes, vol. 39, no. 4, pp. 401-405, 2005.

[76] A. Lafeuillade, G. Hittinger, and S. Chadapaud, "Increased mitochondrial toxicity with ribavirin in HIV/HCV coinfection," The Lancet, vol. 357, no. 9252, pp. 280-281, 2001.

[77] A. Moreno, C. Quereda, L. Moreno et al., "High rate of didanosine-related mitochondrial toxicity in HIV/HCV-coinfected patients receiving ribavirin," Antiviral Therapy, vol. 9, no. 1, pp. 133-138, 2004.

[78] K. Lindahl, L. Stahle, A. Bruchfeld, and R. Schvarcz, "High-dose ribavirin in combination with standard dose peginterferon for treatment of patients with chronic hepatitis C," Hepatology, vol. 41, no. 2, pp. 275-279, 2005.

[79] V. Soriano, M. Puoti, M. Sulkowski et al., "Care of patients coinfected with HIV and hepatitis C virus: 2007 updated 
recommendations from the HCV-HIV International Panel," AIDS, vol. 21, no. 9, pp. 1073-1089, 2007.

[80] A. B. Jesudian and I. M. Jacobson, "Optimal treatment with telaprevir for chronic HCV infection," Liver International, vol. 33, no. 1, pp. 3-13, 2013.

[81] S. Brillanti, F. Buonfiglioli, V. Feletti, L. Laterza, and E. Roda, "Ribavirin priming enhances efficacy of chronic hepatitis $\mathrm{C}$ re-treatment in patients who had not responded to previous combination therapy," Hepatology A, vol. 50, supplement 4, p. 317, 2009.

[82] N. Furusyo, N. Kubo, K. Toyoda et al., "Helper T cell cytokine response to ribavirin priming before combined treatment with interferon alpha and ribavirin for patients with chronic hepatitis C," Antiviral Research, vol. 67, no. 1, pp. 46-54, 2005.

[83] M. Merli, V. Giannelli, F. Gentili et al., "Ribavirin priming improves the virological response to antiviral treatment in transplanted patients with recurrent hepatitis C: a pilot study," Antiviral Therapy, vol. 16, no. 6, pp. 879-885, 2011.

[84] European Association for the Study of the Liver, "EASL Clinical Practice Guidelines: management of hepatitis C virus infection," Journal of Hepatology, vol. 60, no. 2, pp. 392-420, 2014.

[85] V. Leroy, L. Serfaty, M. Bourlière et al., "Protease inhibitor-based triple therapy in chronic hepatitis C: guidelines by the French Association for the Study of the Liver," Liver International, vol. 32, no. 10, pp. 1477-1492, 2012.

[86] E. J. Gane, C. A. Stedman, R. H. Hyland et al., "All-oral sofosbuvir-based 12-week regimens for the treatment of chronic HCV infection: the ELECTRON study," Journal of Hepatology, vol. 58, supplement 1, pp. S6-S7, 2013.

[87] K. V. Kowdley, E. Lawitz, F. Poordad et al., "Safety and efficacy of interferon-free regimens of ABT-450/r, ABT-267, ABT-333 +/ribavirin in patients with chronic HCV genotype 1 infection: results from the AVIATOR study," Journal of Hepatology, vol. 58, supplement 1, p. S2, 2013.

[88] I. Jacobson, E. M. Yoshida, M. Sulkowski et al., "Treatment with sofosbuvir + ribavirin for 12 weeks achieves SVR12 of $78 \%$ in GT2/3 interferon-ineligible, -intolerant, or -unwilling patients: results of the phase 3 POSITRON trial," Journal of Hepatology, vol. 58, supplement 1, p. S28, 2013.

[89] C. Solas, M. Paré, S. Quaranta, and F. Stanke-Labesque, "Evidence-based therapeutic drug monitoring for ribavirine," Therapie, vol. 66, no. 3, pp. 221-230, 2011.

[90] A. Tsubota, Y. Hirose, N. Izumi, and H. Kumada, "Pharmacokinetics of ribavirin in combined interferon-alpha $2 \mathrm{~b}$ and ribavirin therapy for chronic hepatitis $\mathrm{C}$ virus infection," British Journal of Clinical Pharmacology, vol. 55, no. 4, pp. 360-367, 2003.

[91] Y. Arase, K. Ikeda, A. Tsubota et al., "Significance of serum ribavirin concentration in combination therapy of interferon and ribavirin for chronic hepatitis C," Intervirology, vol. 48, no. 2-3, pp. 138-144, 2005.

[92] P. B. Christensen, A. A. Alsio, M. R. Buhl et al., "Ribavirin concentration at week four is an independent predictor for sustained viral response after treatment of hepatitis C genotype 2/3 (Nordynamic Trial)," Journal of Hepatology, vol. 48, supplement 2, pp. S6-S7, 2008. 


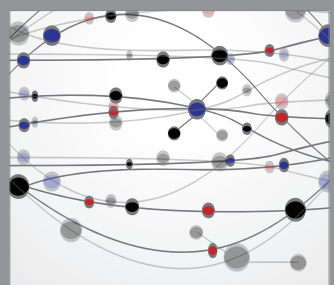

The Scientific World Journal
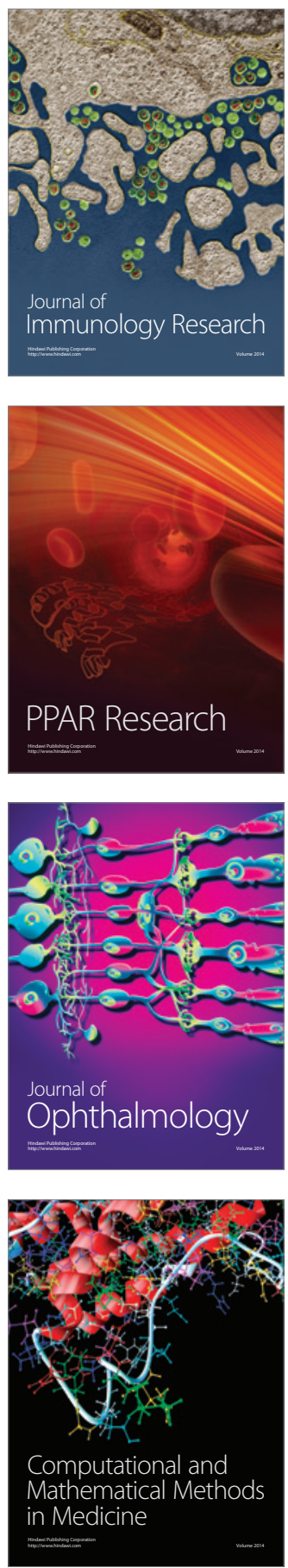

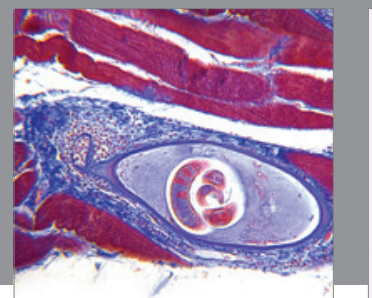

Gastroenterology

Research and Practice
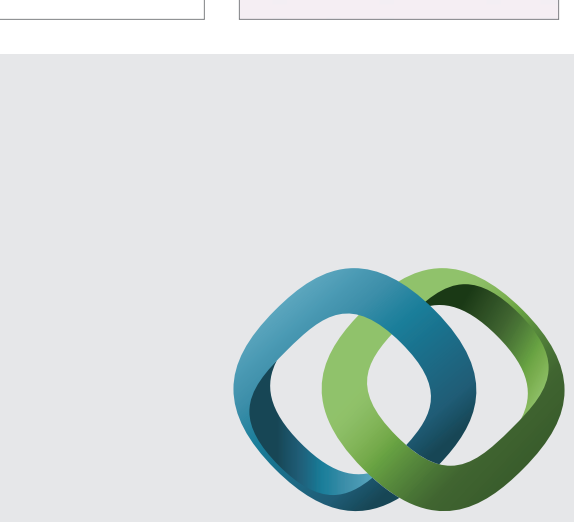

\section{Hindawi}

Submit your manuscripts at

http://www.hindawi.com
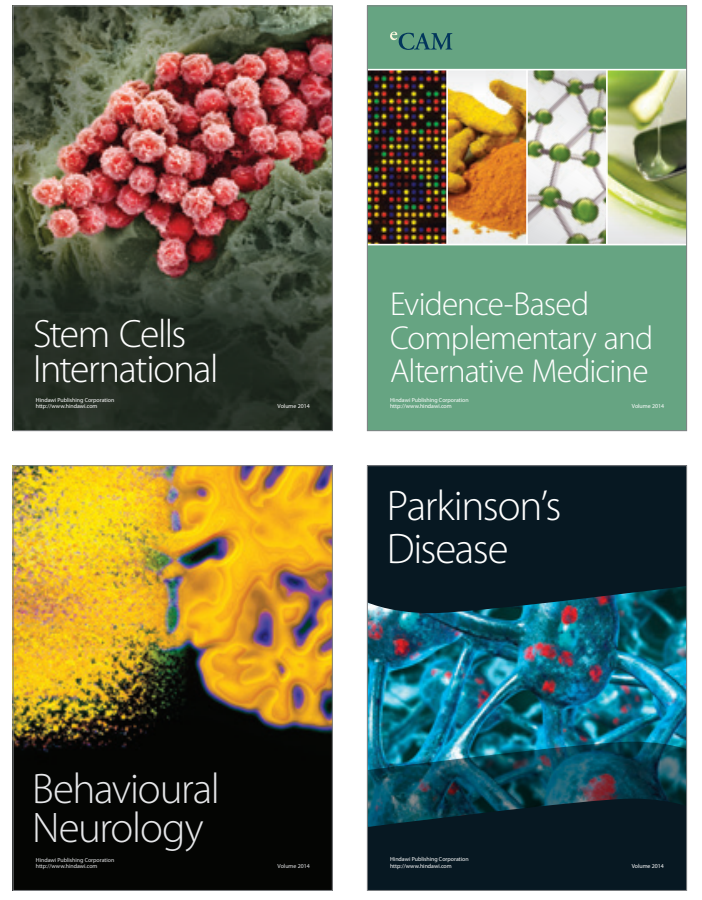
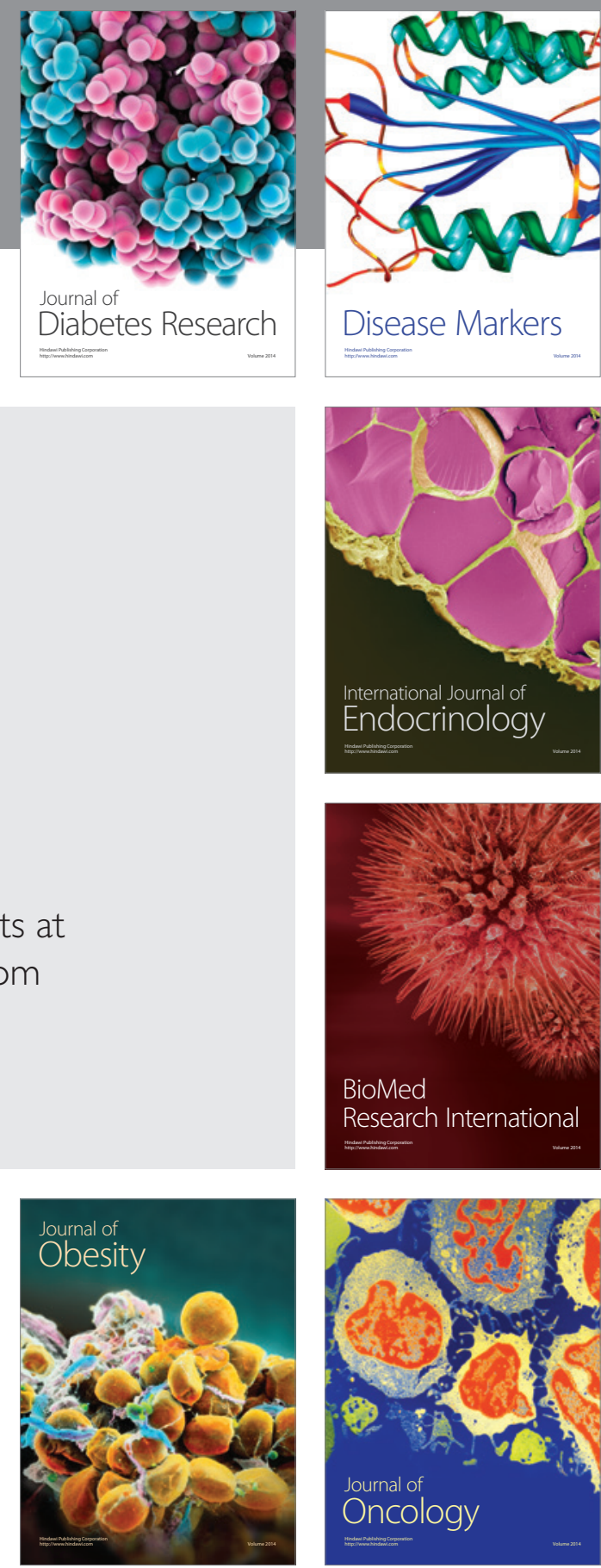

Disease Markers
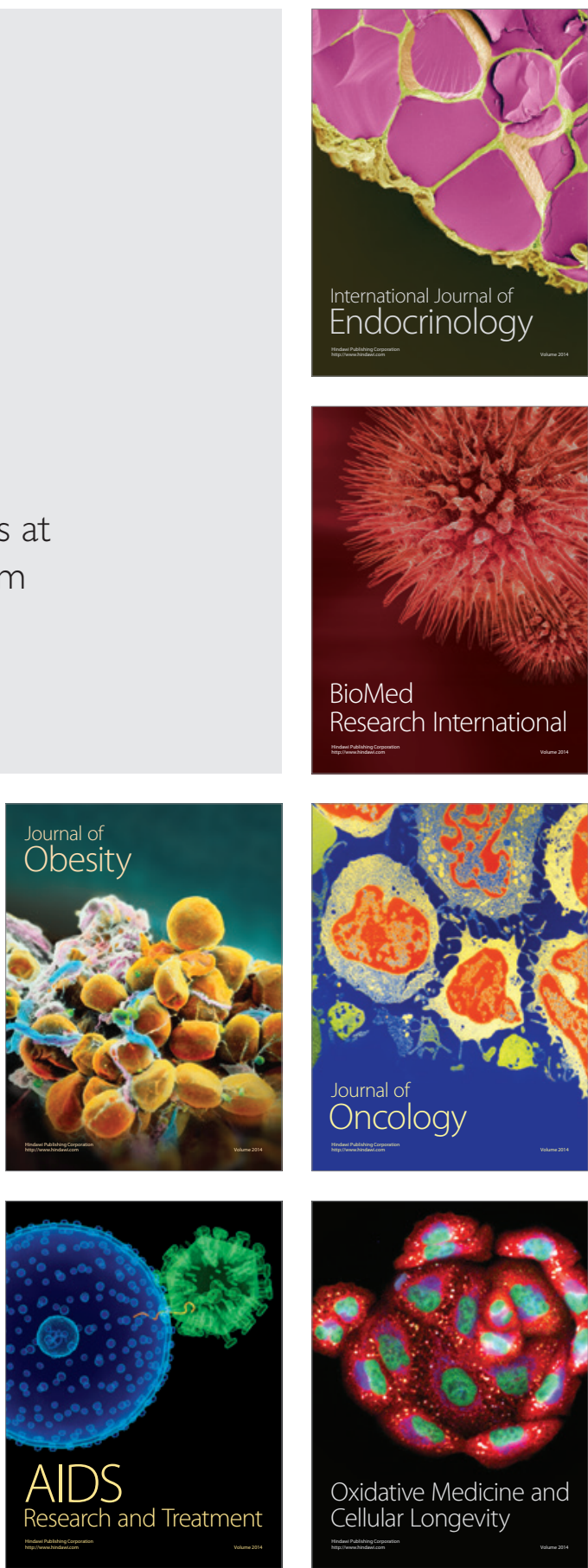